\title{
BREVES ANOTAÇÕES SOBRE A EDUCAÇÃO POLITÉCNICA COMO PARTE DE UM PROJETO EMANCIPADOR
}

BRIEF ANNOTATIONS ON POLYTECHNIC EDUCATION AS A PART OF EMANCIPATING PROJECT

Esther Maria de Magalhães Arantes ${ }^{1}$

Resumo Ao problematizar a crise da modernidade o artigo evidencia os desafios colocados à educação como parte de um projeto emancipador. Endossa a crença dos educadores de que nenhuma mudança estrutural se fará apenas com a educação, embora nenhuma mudança significativa possa se fazer sem ela.

Palavras-chave modernidade; crise; educação.
Abstract The discussion of the 'crisis of modernity' of this article evidences the challenges attributed to education as part of emancipating project. It supports educators' belief that no structural change will happen only with education, although no significant change may be fulfilled without it.

Key words modernity; crisis; education. 


\section{Breves anotações sobre a educação politécnica como parte de um projeto emancipador}

Em artigo anterior (Arantes, Lobo e Fonseca, 2004), escrevemos algumas das idéias que aqui retomamos para iniciar este debate. De acordo com as análises de diversos autores, alguns dos quais apresentadas no texto de Adriana, reconhecemos que este é um momento de crise ética, civilizatória, paradigmática; ou que a modernidade estaria encerrando o seu ciclo e o homem estaria caminhando para um futuro glorioso ou, talvez, para a derrocada final. Uma das características desta crise, de acordo com Boaventura de Sousa Santos, tem sido o predomínio dos processos de exclusão sobre os de inclusão ${ }^{2}$, do capital sobre o trabalho, do mercado sobre a democracia, da propriedade sobre os direitos sociais, resultando no que caracteriza como "fascismo societal"3.

Boaventura sugere que as reflexões sobre os paradigmas societais sejam acompanhadas por reflexões sobre as ciências, na medida em que a maneira de conhecer encontra-se relacionada às práticas sociais. Aceitando este convite, mas sem adentrarmos mais profundamente nas questões propriamente filosóficas e científicas constitutivas da modernidade, é possível, genericamente, dizer que uma de suas características foi ter optado por um certo tipo de razão, de natureza instrumental, capaz de dominar e modificar o meio físico e, na atualidade, a vida, através das biotecnologias.

Nada mal, talvez, se esse tipo de racionalidade científica tivesse se limitado a certos usos e a certos propósitos e não pretendesse ser o único horizonte possível e a única forma de dizer o mundo.

“(...) quando o Ocidente, através de Descartes e de Bacon, fez a escolha por uma forma de cientificidade e deixou de lado tudo o que fosse dotado de alguma ambivalência, deixou de lado também as chamadas idéias obscuras. Com isto, também deixou de lado o que na condição humana é ligado ao corpo, ao tempo, à história e à concretude" (Pessanha, 1993, p. 26).

Não se trata aqui, de acordo com José Américo Pessanha, de negar validade ao modelo das ciências da natureza ou da matemática, mas apenas de reconhecer que as chamadas ciências humanas e sociais não podem se reduzir ao discurso impositivo da razão abstrata, pretendendo a construção de verdades ahistóricas e universais. Assim, quanto mais a razão se fecha em um modelo pretensamente único, maior é o empobrecimento do pensamento, a domesticação da vida e a intolerância à diferença. Trata-se, portanto,

“(...) de negar a matematização daquilo que não é matematizável, de negar a desumanização daquilo que precisa se manter humanizado, negar a extração da di- 
mensão temporal daquilo que só pode ser compreendido temporalmente. Tratase, portanto, de preservar a temporalidade do tempo, a humanidade do homem, a concretude do concreto, coisas óbvias" (Pessanha, 1993, p. 31).

Diante dessas poucas ponderações, mas, esperamos, suficientes para os propósitos da interlocução aqui pretendida, uma pergunta se impõe: se de há muito sabemos disto, se somos há tanto tempo capazes de uma crítica às pretensões do pensamento único, por que este modelo continua vitorioso?

Embora o pensamento de Karl Marx seja atualmente pouco lembrado - quem sabe na tentativa de nos convencer de que o capitalismo é a verdadeira natureza das sociedades -, não podemos problematizar essa racionalidade científica sem mencionarmos que ela se encontra, mais do que nunca, articulada ao capital. Assim, esta modernidade da qual falamos não é outra, senão ocidental e capitalista.

Carlos Henrique Escobar (2000) nos lembra que não se trata, em Marx, apenas da questão do roubo do sobre-trabalho, mas também, fundamentalmente, do fetiche da mercadoria. Neste sentido, não é suficiente a luta contra a exploração do trabalho, mas é necessário ir além e criticar a sociedade fundada no entusiasmo e no maravilhamento da mercadoria, da acumulação e do dinheiro. Segundo ele, é preciso que as pessoas possam se reencontrar de uma outra forma: fora dos valores do capital.

Escobar nos ensina que o capital tem apenas visão de meios: a vida é apenas um meio de acumulação e riqueza, e de ampliação de poder. A razão também não tem sido uma tática de aproximação das questões, mas instrumento: produz e faz a guerra. Por isso é que o mundo em que vivemos tem sido também, ao lado de um fantástico desenvolvimento tecnológico, a história da depredação da terra e da humilhação da vida.

“O capital inventou um mundo, inventou o homem, inventou esta roupa, esta cara, as línguas nacionais. É dele tudo isto, mesmo que alguém do povo o auxilie, como, por exemplo, na organização do trabalho. Mas o capital produziu tudo isto em função da intensificação da produção e da capacitação para a guerra. Só que agora o capital chegou a uma espécie de meio pleno, que é a cibernética, a automação, o robô, a clonagem. Com isto ele dispensa a vida: são as massa excluídas (...). O capital não faz mais a guerra com soldados; se o fizer, perde a guerra. Também não produz mercadorias apenas com trabalhadores: ela não é competitiva. Ao excluir a vida, o capital vai suspender tudo o que ele fez" (Escobar, 2000).

Nesse sentido, no capitalismo globalizado de hoje, a crise pode ser definida como sendo o desmonte dos valores, das temáticas e dos corpos da modernidade. 
“O capital está desfazendo a cidade, a mulher-mãe, a família triangular, o dispositivo criança, o trabalhador. Ele não precisa mais destes corpos e destas identidades (...) estamos muito soltos (...) uma espécie de nomadismo interior e exterior. Esta globalização desengajou o social. Ela não precisa mais do social, dos lugares, das cidades e das marcas. A Terra, agora, é controlada por satélites. A informação, as mídias, a Otan, a dívida externa, tudo isto é fixo e parado: imobiliza as ações aqui em baixo (...). A História não era aquilo que a esquerda falava: o sentido das coisas e tal. Era, na verdade, a memória do capital" (Escobar, 2000).

Escobar acredita que as alternativas aos valores do capital não têm sido apresentadas, e por isso não vislumbra, no momento atual, como poderíamos abandonar os lugares onde existam lutas. Nesse sentido, Moacir Gadotti (1980), ao falar do papel do educador, lembra que uma mudança na educação não se fará espontaneamente, nem de um momento para o outro, por isso advoga uma "pedagogia do conflito" ou uma "educação contra a educação", capaz de mantê-la permanentemente em questão. Este estado de permanente "tensão" ou "conflito" não resolve as questões colocadas por Escobar, que não se limitam ao aparelho escolar e universitário, mas impede que a educação seja reduzida a um mero "aparelho ideológico" (no sentido das teorias da reprodução vigentes na década de 1970), podendo estimular, mais do que limitar, o pensamento crítico e criativo.

No texto de Adriana Geisler, a concepção politécnica da educação, entendida como parte de um projeto emancipador, deve possibilitar a experiência de valores e atitudes que se distanciam da ideologia liberal. Longe de se pautar pelas demandas e objetivos do mercado, a proposta da formação politécnica busca incorporar a dimensão reflexiva ao trabalho produtivo. Ou seja, possibilitar uma experiência do trabalho e do pensamento que se distancie dos valores do capital, criando condições para sua superação.

Assim como os autores aqui mencionados, Adriana não desconhece os desafios e as dificuldades implicadas na construção de tal projeto, dada a tendência atual de transformar problemas éticos e políticos em problemas técnicos e/ou jurídicos; de substituir as políticas públicas pela livre negociação no mercado, e pela colonização da subjetividade por processos midiáticos e de consumo, nos fazendo indiferentes ao sofrimento do outro - que, no Brasil, são permanências históricas: a tortura, os processos de exclusão, as execuções.

Para finalizar, vale dizer que, em geral, os educadores acreditam que nenhuma mudança estrutural se fará apenas com a educação, embora nenhuma mudança significativa possa se fazer sem ela. Esta é a aposta de Adriana com a qual estamos de acordo. 


\section{Notas}

${ }^{1}$ Professora da Universidade do Estado do Rio de Janeiro (Uerj) e da Pontifícia Universidade Católica do Rio de Janeiro (PUC-Rio). Coordenadora da Comissão Nacional de Direitos Humanos do Conselho Federal de Psicologia. Doutora em Educação Humanística e do Comportamento pela Universidade de Boston (EUA).<arantes@psi.puc-rio.br>

2 Segundo José de Souza Martins (1977, p. 32), são próprias à lógica do capitalismo a inclusão e a exclusão: "A sociedade capitalista desenraíza, exclui, para incluir de outro modo, segundo suas próprias regras, segundo sua própria lógica".

${ }^{3}$ Esclarece Santos (1999, p. 52) que não se trata de um regresso ao fascismo dos anos 1930 e 40, mas da criação, por exemplo, de uma cartografia urbana "dividida em zonas selvagens e civilizadas", e que estaria prestes a "transformar-se num critério geral de sociabilidade", sendo comum tanto à ação estatal quanto à não estatal.

\section{Referências}

ARANTES, Esther M. M.; LOBO, Lilia F.; FONSECA, Tânia M. G. 2004. Pensar: a que será que se destina? Diferentes tempos de uma reflexão sobre a morte anunciada do educador. Psicologia \& Sociedade, v. 16, n. 1, p. 50-68. Edição especial.

ESCOBAR, Carlos Henrique. 2000. Marxismo hoje: críticas e perspectivas históricas. (Mimeo). Anotações da aula inaugural do Curso de Extensão de Direito Social do Programa Cidadania e Direitos Humanos na Universidade do Estado do Rio de Janeiro.

GADOTTI, Moacir. 1980. Educação e poder: introdução a uma pedagogia do conflito. São Paulo: Cortez.
MARTINS, José de S. 1997. Exclusão social e a nova desigualdade. São Paulo: Paulus.

PESSANHA, José Américo. 1993. Filosofia e modernidade: racionalidade, imaginação e ética. Cadernos Anped, n. 4, p. 7-36.

SANTOS, Boaventura S. 1999. Reinventar a democracia: entre o pré-contratualismo e o pós-contratualismo. In: HELLER, Agnes (org.). A crise dos paradigmas em ciências sociais e os desafios para o século XXI. Rio de Janeiro: Contraponto, p. 33-75. 
